\title{
Needle stick injuries and awareness towards post exposure prophylaxis for HIV among private general practitioners of Davangere city
}

\author{
Navinkumar Angadi*, Shubha Davalgi, Vanitha SS
}

Department of Community Medicine, JJM Medical College, Davangere, Karnataka, India

Received: 17 November 2015

Accepted: 18 December 2015

\section{*Correspondence:}

Dr. Navinkumar Angadi,

E-mail: navinkumarangadi7@gmail.com

Copyright: () the author(s), publisher and licensee Medip Academy. This is an open-access article distributed under the terms of the Creative Commons Attribution Non-Commercial License, which permits unrestricted non-commercial use, distribution, and reproduction in any medium, provided the original work is properly cited.

\begin{abstract}
Background: Health care workers are at increased risk of infection with blood borne pathogens. Most exposures among health care workers are caused by percutaneous injuries with sharp objects contaminated with blood or body fluids. HIV post-exposure prophylaxis (PEP) is effective in preventing potential HIV infection following accidental exposure. The objective of the study was to determine the prevalence of needle stick injuries (NSI) and factors affecting NSI among private general practitioners, awareness towards post exposure prophylaxis for HIV among private general practitioners, practice of post exposure prophylaxis for HIV among private general practitioners.

Methods: The Cross-sectional, questionnaire-based study was conducted among private general practitioners of Davangere city.

Results: The prevalence of needle stick injures (NSI) in the life time of private general practitioners was $92.4 \%$. In our study all participants had heard of HIV post exposure prophylaxis (PEP). Out of 150, 12 (8\%) had accidental exposure and $8(67 \%)$ received HIV-PEP after exposure. Out of $8,3(38 \%)$ completed the full HIV-PEP course.

Conclusions: Majority of the respondents had needle stick injuries at least once in their life time. Majority of respondents had NSI while recapping needle. Majority of the participants had good level of awareness on PEP. Despite of good level of awareness they fail to practice HIV PEP.
\end{abstract}

Keywords: Needle stick injury, Post exposure prophylaxis, Private general practitioners

\section{INTRODUCTION}

Health care workers are at increased risk of infection with blood borne pathogens like hepatitis $\mathrm{B}$ and $\mathrm{C}$ viruses (HBV, HCV) and the human immunodeficiency virus (HIV) because of their occupational exposure to blood and other body fluids. Most exposures among health care workers are caused by percutaneous injuries with sharp objects contaminated with blood or body fluids. These sharps include needles, scalpels, lancets and broken glass 1 .

According to World Health Report 2002, out of 35 million health-care workers, 2 million experience percutaneous exposure to infectious diseases each year. It further notes that $37.6 \%$ of Hepatitis B, $39 \%$ of Hepatitis $\mathrm{C}$ and $4.4 \%$ of HIV/AIDS in Health Care Workers around the world are due to needle stick injuries. ${ }^{2}$

Needle stick Injuries (NSIs) are defined as an accidental skin penetrating stab wound caused by hollow-bore needles such as hypodermic needles, blood-collection needles, IV catheter stylets, and needles used to connect parts of IV delivery system. ${ }^{3}$

According to WHO Bulletin 2003, 30\% to $50 \%$ of all needle injuries occur during clinical procedures ${ }^{4}$.The incidence of NSI is considerably higher than current estimates, due to gross under-reporting. The Centres for Disease Control (CDC), 2007 estimates that about 
$6,00,000$ to $10,00,000$ needle stick injuries occur each year. Unfortunately, about half of these needle stick injuries go unreported. In USA $6,00,000$ to $10,00,000$ receive NSI from conventional needles and sharps every year, while in UK it is $1,00,000 \mathrm{HCW}$ /year. In India, authentic data on NSI are scarce.,

Occupational percutaneous exposures to blood borne pathogens can be prevented by strategies like immunization against $\mathrm{HBV}$, scrupulous and consistent application of universal precautions and post exposure prophylaxis (PEP) to prevent the development of disease. But in many countries, it has not been possible to implement these strategies because of lack of data on disease burden associated with occupational exposure to blood borne pathogens. ${ }^{1}$

Post exposure prophylaxis (PEP) refers to comprehensive medical management to minimise the risk of infection among Health Care Personnel (HCP) following potential exposure to blood-borne pathogens (HIV, HBV, and HCV). This includes counselling, risk assessment, relevant laboratory investigations based on informed consent of the source and exposed person, first aid and depending on the risk assessment, the provision of short term (four weeks) of antiretroviral drugs, with follow up and support. Centre for Disease Control (CDC) and National AIDS Control Organization (NACO) recommend PEP for workers with needle stick injuries. PEP for HIV exposure is best when started within golden period of $<2$ hours and there is little benefit after 72 hours. If started soon after exposure, PEP can reduce the risk of HIV infection by over $80 \%$. The prophylaxis needs to be continued for 28 days. PEP is available as either basic regimen (2 Nucleoside Reverse Transcriptase Inhibitor (NRTI)) or expanded regimen (2NRTI and 1 PI drugs). NACO recommend Zidovudine/Stavudine + Lamivudine (basic regimen) and Zidovudine + Lamivudine + Lopinavir/ Ritonavir (expanded regimen), and its available free of cost at all Anti-Retroviral Therapy Centres (ARTCs) and Integrated Counselling \& Testing Centres (ICTCs).,

Adherence to a full 28-day course of ARVs is critical to the effectiveness of the intervention. Recent evidence shows PEP uptake has been insufficient: only $57 \%$ of the people who initiated PEP have completed the full course 9 . Various studies done in past were institutional based focussing more on interns, nursing students with very little data available among general private practitioners. With this background the present study has been undertaken. ${ }^{10-15}$

The objective of the study was to determine the prevalence of needle stick injuries (NSI) and factors affecting NSI among private general practitioners, awareness towards post exposure prophylaxis for HIV among private general practitioners, practice of post exposure prophylaxis for HIV among private general practitioners.

\section{METHODS}

This cross sectional study was conducted for 3 months from 1st January to $31^{\text {st }}$ March 2015 among 150 private allopathic general practitioners of davangere city. After taking consent private practitioners were interviewed using pre-designed, pre-tested, semi-structured questionnaire was used. Statistical analysis was done by using proportion

\section{Inclusion criteria}

1. All qualified, registered allopathic private general Practitioners of Davangere city.

2. Private general practitioners who had work experience at least one year.

\section{Exclusion criteria}

1. All practitioners who were not cooperative and did not consent for the study.

2. All consultants of nursing home and teaching hospitals.

\section{RESULTS}

Table 1: The prevalence of needle stick injuries and factors affecting needle stick injuries among private general practitioners.

\begin{tabular}{|lll|}
\hline Variable & Number & $\%$ \\
\hline Have you had needle stick injury in & 86 & 15.7 \\
the past 1 year & & \\
\hline Frequency of needle stick injuries & & \\
experienced last one year & 40 & 47 \\
Once & 36 & 42 \\
2-5 times & 10 & 12 \\
\hline 5 times & & \\
\hline When u had needle stick injury & 42 & 49 \\
(Procedure)? & 17 & 20 \\
Recapping a needle & 9 & 10 \\
During injection, puncture & 11 & 13 \\
During intravenous line insertion & 8 & 9 \\
During blood collection & 19 & 22 \\
During the intervention by instrument & 6 & 7 \\
Surgical blade injury & & \\
By disposing to the sharps container & & \\
\hline Factors influenced for needle stick & & \\
injury & 40 & 47 \\
Heavy workload & 26 & 30 \\
Lack of protection measures & 41 & 48 \\
inattention, hasty work & 14 & 16 \\
Tiredness & & \\
\hline After needle stick injury did you get & & 37 \\
tested for & 32 \\
HIV & 1 & 1 \\
HBV & 0 & 0 \\
HCV others(specify) & & \\
\hline
\end{tabular}


Table 2: Awareness about HIV post exposure prophylaxis among study participants.

\begin{tabular}{|c|c|c|}
\hline Variable & Number & Percentage \\
\hline \multicolumn{3}{|l|}{ Heard of HIV- PEP } \\
\hline yes & 150 & $100 \%$ \\
\hline no & 0 & $0 \%$ \\
\hline \multicolumn{3}{|c|}{ HIV PEP is effective in preventing HIV transmission } \\
\hline Yes & 125 & 83 \\
\hline No & 25 & 17 \\
\hline \multicolumn{3}{|c|}{$\begin{array}{l}\text { The proportion of needle stick injuries result in HIV } \\
\text { transmission }\end{array}$} \\
\hline $1 / 100$ & 27 & 18 \\
\hline $1 / 500$ & 25 & 17 \\
\hline $3 / 1000$ & 82 & 55 \\
\hline $10 / 1000$ & 16 & 10 \\
\hline \multicolumn{3}{|c|}{ The fluids that can transmit HIV } \\
\hline Breast milk & 139 & 93 \\
\hline Urine/ faeces & 28 & 19 \\
\hline peritoneal fluid & 103 & 69 \\
\hline synovial fluid & 88 & 59 \\
\hline pleural fluid & 96 & 64 \\
\hline Saliva cerebrospinal fluid & 73 & 49 \\
\hline Cerebro spinal fluid & 110 & 73 \\
\hline $\begin{array}{l}\text { Initial first aid measure to } \\
\text { institute following needle } \\
\text { stick injury? }\end{array}$ & 17 & 11 \\
\hline $\begin{array}{l}\text { Promote active bleeding of } \\
\text { wound }\end{array}$ & 121 & 81 \\
\hline $\begin{array}{l}\text { Wash thoroughly with soap } \\
\text { and water don't know }\end{array}$ & 13 & 9 \\
\hline $\begin{array}{l}\text { The following are high risk } \\
\text { exposures for HIV } \\
\text { transmission }\end{array}$ & 58 & 39 \\
\hline Percutaneous injuries & 8 & 5 \\
\hline $\begin{array}{l}\text { Exposure of intact skin to } \\
\text { body fluids }\end{array}$ & 73 & 49 \\
\hline Mucus membrane exposure & & \\
\hline Exposure of broken skin & 125 & 83 \\
\hline $\begin{array}{l}\text { How soon after needle stick } \\
\text { injury should PEP be } \\
\text { commenced }\end{array}$ & 78 & 52 \\
\hline $\begin{array}{l}\text { As soon as possible/ within } \\
72 \text { hours }\end{array}$ & 66 & 44 \\
\hline After 72 hours don't know & 6 & 4 \\
\hline \multicolumn{3}{|c|}{$\begin{array}{l}\text { The ideal HIV-PEP regimen following high risk needle } \\
\text { stick injury }\end{array}$} \\
\hline One drug regimen & 14 & 9 \\
\hline 2- drug regimen & 90 & 60 \\
\hline Expanded drug regimen & 46 & 31 \\
\hline \multicolumn{3}{|c|}{ What is the duration of HIV -PEP } \\
\hline 1 week & 12 & 8 \\
\hline 2 weeks & 13 & 9 \\
\hline 4 weeks & 106 & 71 \\
\hline 3 weeks & 19 & 12 \\
\hline \multicolumn{3}{|c|}{$\begin{array}{l}\text { Should HIV-PEP be administered for accidental non- } \\
\text { occupational exposure to HIV }\end{array}$} \\
\hline Yes & 136 & 91 \\
\hline No & 14 & 9 \\
\hline
\end{tabular}

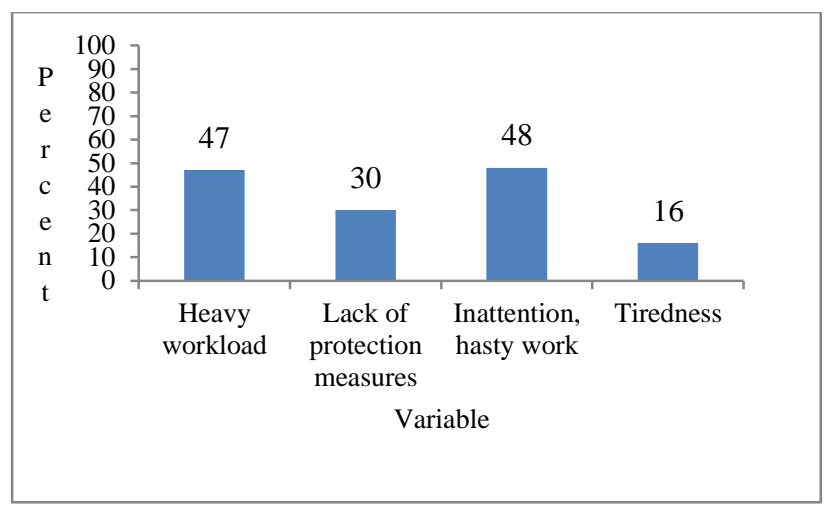

Figure 1: Factors affecting NSI among private general practitioners.

In the present study $84(56 \%)$ were males and $66(44 \%)$ females. The prevalence of needle stick injures (NSI) in the life time was $92.4 \%$ and in the past one year was $15.7 \% .40(47 \%)$ had needle stick injury only once and $36(42 \%)$ had $2-5$ times in the last one year. $42(49 \%)$ had needle stick injuries while recapping needle, 17 (20\%) during injection, puncture and $11(13 \%)$ while collecting the blood sample. After NSI 33 (38\%) and 32 (37\%) had tested for HBV and HIV respectively and remaining 84 haven't undergone for any tests. (See table 1). Most common cause for NSI was heavy work load $37.9 \%$ followed by inattention and hasty work (Figure 1).

\section{Awareness towards post exposure prophylaxis for $\mathrm{HIV}$ among private general practitioners}

In our study all 150 private practitioners had heard of HIV post exposure prophylaxis (PEP). Out of 150 who had heard of HIV-PEP, $125(83 \%)$ told that it is effective in preventing HIV transmission. 82 (55\%) answered correctly the proportion of needle stick injuries result in HIV transmission.139 (93\%) told breast milk, 103 (69\%) told peritoneal fluid and $28(19 \%)$ told urine/ faeces can transmit HIV. $121(81 \%)$ answered correctly the first aid to institute following needle stick injury.125 (83\%) answered exposure of broken skin is the high risk exposure for HIV transmission.78 (52\%) told PEP should be commenced as soon as possible/ within 72 hours. 90 (60\%) answered two drug regimen and only 46 (31\%) answered correctly the ideal HIV-PEP regimen following high risk needle stick injury. $106(71 \%)$ answered correctly the duration of HIV-PEP. 136 (91\%) told HIVPEP should be administered for accidental nonoccupational exposure to HIV (Table 2).

\section{Practice of post exposure prophylaxis of HIV among private practitioners}

In our study out of $150,12(8 \%)$ had accidental exposure to HIV in the past. Only $8(67 \%)$ received HIV-PEP after exposure. Out of $8,3(38 \%)$ completed the full HIV-PEP course. The reasons for not commencing HIV-PEP were: 
1. Not aware of PEP protocol at that time.

2. Assumed exposure source was negative.

\section{DISCUSSION}

In the present study $92 \%$ had NSI in their life time and $15 \%$ in the last one year and almost similar finding was observed by fullerton $\mathrm{M}$ et al $(17.8 \%$ in the last one year) and Bayapa Reddy $\mathrm{N}$ et al $(84.8 \%$ in their life time and $15.7 \%$ in the past three months. ${ }^{16,17}$ In a study conducted by Patricia A et al, $69.4 \%$ of the respondents reported history of needle stick injuries. ${ }^{18}$

In the present study $47 \%$ had needle stick injury only once which is higher than the study conducted by yousafzai et al $(26.7 \%)$ and lower than study conducted by fullerton et al $(75.6 \%) .{ }^{16,19}$ In the present study $42 \%$ had 2-5 times in the last one year and which is lower than study conducted by fullerton et al $(21.9 \%){ }^{16}$

In the present study most of the participants had NSI while recapping the needle and similar finding was observed in the study conducted by Yousafzai et al and bayappa reddy $\mathrm{N}$ et al. ${ }^{17,19}$ In the present study the most common factor influenced NSI was hasty work and similar finding was observed in the study conducted by Bayappa Reddy $\mathrm{N}$ et al. ${ }^{17}$

In our study all private practitioners had heard of HIV post exposure prophylaxis (PEP) and almost similar finding was observed by Patricia A et al $(98 \%) .{ }^{18}$ Our study observation is higher than the other studies conducted by $\mathrm{C}$ Ooi et al $(68 \%)$ and Biniam Mathewos et al $(48 \%){ }^{20,21}$ In the present study $81 \%$ told HIV (PEP) is effective in preventing HIV transmission, which is lower than study conducted by Patricia A et al $(99.4 \%) .{ }^{18}$ It is higher than study conducted by Biniam Mathewos et al $(60.5 \%)^{21}$

In our study $55 \%$ respondents correctly identified the risk of transmission of HIV from a NSI to be around three per 1000 injuries and similar finding was observed by Patricia A et al. ${ }^{18}$ Regarding knowledge of various high risk body fluids for HIV transmission, the following proportions were obtained for correct identification of the following body fluids as high risk for HIV transmission: breast milk 93\%, peritoneal fluid $69 \%$ and $19 \%$ incorrectly identified urine, saliva and faeces respectively as high-risk fluids for HIV transmission and almost similar finding was observed by Patricia et al. ${ }^{18} 49 \%$ and $39 \%$ identified mucous membrane exposure and percutaneous injuries were high-risk exposures for HIV transmission respectively. Our study observations are lower than study conducted by Patracia et al. ${ }^{18}$

52\% told PEP should be commenced as soon as possible/ within 72 hours which is higher than study conducted by patracia et al (93.9\%) and Bayappa Reddy $\mathrm{N}$ et al $(80 \%) .{ }^{17,18}$ In the study conducted by C Ooi et al $24.6 \%$ were aware of the 72 hour time restrictions. ${ }^{20}$
In our study $31 \%$ answered correctly the ideal HIV-PEP regimen following high risk needle stick injury and similar finding was observed by patracia et al $(32.7 \%){ }^{18}$ In present study $71 \%$ answered correctly the duration of HIV-PEP which is lower than study conducted by Patracia et al. ${ }^{18} 91 \%$ told HIV-PEP should be administered for accidental non-occupational exposure to HIV which is higher than study conducted by Patracia et al $(61 \%){ }^{18}$

In the present study $8 \%$ had accidental exposure to HIV which is lower than study conducted by Getahun Kebede Beyera et al (Of $162 \mathrm{HCWs}$ ) and study conducted by Biniam Mathewos et al $(33.8 \%){ }^{21}$ In our study $67 \%$ received PEP compare to $25.3 \%$ in the study of Getahun Kebede Beyera et $\mathrm{al}^{21}$ and $74.2 \%$ in Biniam Mathewos et al. $^{22}$

\section{CONCLUSION}

We conclude that Needle Stick Injuries (NSI) were common among private general practitioners. Majority of the respondents had needle stick injuries at least once in their life time. Majority of them had NSI while recapping needle and injection procedure. Most common cause for NSI was heavy work load followed by inattention and hasty work. Majority of the study participants had good level of awareness on PEP. Despite of good level of awareness they fail to practice HIV PEP following accidental exposure to HIV/ AIDS risk factors. So a knowledge-practice gap is existing among private general practitioners.

\section{Recommendations}

1. Further research in large scale is needed to determine the actual incidence of NSI and sharp injury exposure.

2. There is a need to include universal precautions, biological waste disposal and PEP as a continued education workshop for medical practitioners.

3. Medical practitioners have to be serious about needle stick injuries, protecting themselves with Hepatitis B vaccination, universal precautions, and post-exposure prophylaxis for HIV.

4. Private general practitioners should provide written guidelines and protocols of HIV PEP at the workplace.

\section{ACKNOWLEDGMENTS}

I am thankful to all private practitioners who were part of the study for their kind co-operation. I also thank my colleagues, post graduate students for their support during the course of the study.

\section{Funding: No funding sources Conflict of interest: None declared}

Ethical approval: The study was approved by the Institutional Ethics Committee 


\section{REFERENCES}

1. Prüss-Üstün A, Rapiti E, Hutin Y. Sharps injuries: Global burden of disease from sharps injuries to health-care workers. Environmental Burden of Disease Series, No. 3. WHO. Protection of the Human Environment Geneva, 2003.

2. Needle stick injuries. Protecting health-care workers - preventing needle stick injuries World health organization. Available at URL: http://www.who.int/en/ accessed on 12/03/2015.

3. Centers for Disease Control and Prevention, 2008. Workbook for Designing, Implementing, and Evaluating a Sharps Injury Prevention Program. www.cdc.gov/sharpssafety/pdf/sharpsworkbook_20 08.pdf.

4. Hutin Y. Best infection control practices for intradermal, subcutaneous and intramuscular needle injections. Bulletin of WHO. 2003;81(7).

5. National Institute for Occupational Safety and Health (NIOSH) Alert: Preventing needle stick injuries in healthcare settings. Washington DC: NIOSH, 1999.

6. Centre for disease control \& prevention. Available from:

URL: www.cdc.gov/ncidol/hip/guide/phspep/htm.

7. Antiretroviral Therapy Guidelines for HIV-Infected Adults and Adolescents Including Post-exposure Prophylaxis. NACO, Ministry of Health and Family Welfare, Government of India, 2007.

8. Updated US Public Health Service guidelines for the management of occupational exposures to HIV and recommendations for post-exposure prophylaxis. CDC MMWR Morb Mortal Wkly Rep. 2005;54:1-24.

9. Post-exposure prophylaxis to prevent HIV infection. World health organization Factsheet 1 December 2014. Available at URL: http://www.who.int/en/. Accessed on 12/03/2015.

10. Jaber MA. A survey of needle sticks and other sharp injuries among dental undergraduate students. International journal of infection control. 2011;7(3).

11. Lukianskyte R, Gataeva J, Radziunaite L. Needle sticks and sharps injuries experienced by staff nurses and nursing students and their prevention. International jurnal of infection control. 2012;8(1).

12. Ekundayo OT, Emovon O. Knowledge, attitude and practice of human immunodeficiency virus infection post-exposure prophylaxis among resident doctors in a tertiary hospital, benin city, Nigeria. International Journal of Community Research. IJCR. 2014;3(3):68-73.
13. Muralidhar S, Singh PK, Jain RK, Malhotra M. Needle stick injuries among health care workers in a tertiary care hospital of India Indian J Med Res. 2010:405-410.

14. Baheti AD, Tullu MS, Lahiri KR. Awareness of Health Care Workers Regarding Prophylaxis for Prevention of Transmission of Blood-Borne Viral Infections in Occupational Exposures. Al Ameen J Med Sci. 2010;3(1):79 -83.

15. Radha R, Asif Khan. Epidemiology of needle sticks injuries among the health care workers of a rural tertiary care hospital - a cross-sectional study. National Journal of Community Medicine. 2012;4(3):589-94.

16. Fullerton M, Gibbons V. Needle stick injuries in a healthcare setting in New Zealand New Zealand Med J. 2011;124(1335):33-9.

17. Bayapa Reddy N, Piramanayagam A, Pallavi M, Singh RK, Nagarjuna Reddy N, Pirabu RA. Prevalence of needle-stick injuries, knowledge of universal precautions and post exposure prophylaxis among private medical practitioners of Madurai city, Tamilnadu. Nat J Res Com Med. 2012;1(3):123-77.

18. Agaba PA, Agaba EI, Ocheke AN, Daniyam CA, Akanbi MO. Awareness and knowledge of human immunodeficiency virus post exposure prophylaxis among Nigerian Family Physicians. Niger Med J. 2012;53(3):155-60.

19. Yousafzai MT, Nisar N, Kakakhel MF, Qadri MH, Khalil R, Hazara SM. Injection practices among practitioners in private medical clinics of Karachi, Pakistan. East Mediterr Health J. 2013;19(6):570-5.

20. Ooi C, Dayan L, Yee L. Knowledge of post exposure prophylaxis (PEP) for HIV among general practitioners in northern Sydney. Sexually transmitted infection journal. Sex Transm Infect. 2004;80(5):420.

21. Mathewos B, Birhan W, Kinfe S, Boru M, Tiruneh G, Addis Z, et al. Assessment of knowledge, attitude and practice towards post exposure prophylaxis for HIV among health care workers in Gondar, North West Ethiopia. BMC Public Health. 2013;13:508.

22. Beyera GK, Chercos DH. Post exposure prophylaxis uptake against exposure to HIV/AIDS risk factors in healthcare settings was very low. International Journal of Infection Control. 2015;11(2).

Cite this article as: Angadi N, Davalgi S, Vanitha SS. Needle stick injuries and awareness towards post exposure prophylaxis for HIV among private general practitioners of Davangere city. Int J Community Med Public Health 2016;3:335-9. 